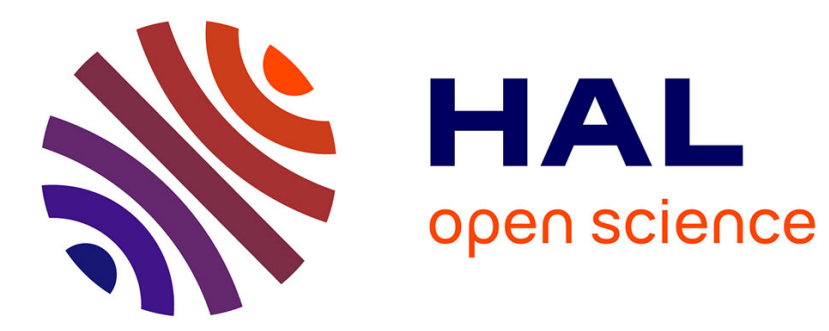

\title{
Electromagnetic field propagation in a composite laminate and induced thermal field
}

Anaïs Barasinski, Chady Ghnatios, Erik Abenius, Stephane Bechtel, Francisco Chinesta

\section{- To cite this version:}

Anaïs Barasinski, Chady Ghnatios, Erik Abenius, Stephane Bechtel, Francisco Chinesta. Electromagnetic field propagation in a composite laminate and induced thermal field: Application to microwave composites processing. International Journal of Material Forming, 2021, 14 (1), pp.97-103. 10.1007/s12289-020-01562-z . hal-03159374

\section{HAL Id: hal-03159374 \\ https://hal.science/hal-03159374}

Submitted on 4 Mar 2021

HAL is a multi-disciplinary open access archive for the deposit and dissemination of scientific research documents, whether they are published or not. The documents may come from teaching and research institutions in France or abroad, or from public or private research centers.
L'archive ouverte pluridisciplinaire HAL, est destinée au dépôt et à la diffusion de documents scientifiques de niveau recherche, publiés ou non, émanant des établissements d'enseignement et de recherche français ou étrangers, des laboratoires publics ou privés. 


\title{
Electromagnetic field propagation in a composite laminate and induced thermal field
}

\author{
Application to microwave composites processing
}

\author{
Anais Barasinski ${ }^{1} \cdot$ Chady Ghnatios $^{2} \cdot$ Erik Abenius $^{3} \cdot$ Stephane Bechtel $^{4} \cdot$ Francisco Chinesta $^{5}$
}

\begin{abstract}
Microwave (MW) technology relies on volumetric heating, where thermal energy is induced from an electromagnetic field. Nowadays, the main drawback of this technology is that the complex physics involved in the conversion of electromagnetic energy into thermal energy is not entirely understood and controlled. The main objective of this work is to model, simulate and validate the interactions of microwaves with a composite laminate consisting of a stack of unidirectional layers composed of a resin matrix and carbon fibers, to predict its heating. Once validated, this simulation tool will serve to predict, control and optimize composites forming processes.
\end{abstract}

Keywords Composite $\cdot$ Thermoplastic $\cdot$ Electromagnetic heating $\cdot$ Microwaves $\cdot$ Coupling

\section{Introduction}

Composites are major protagonists in many industries and activity sectors, among them transport industries (aeronautic and automotive). This is mainly due to the combination

Anais Barasinski

anais.barasinski@univ-pau.fr

Chady Ghnatios

cghnatios@ndu.edu.lb

Erik Abenius

Erik.Abenius@esi-group.com

Stephane Bechtel

stephane.bechtel@airbus.com

Francisco Chinesta

Francisco.Chinesta@ensam.eu

1 E2S UPPA, CNRS, IPREM, Université de Pau et des Pays de l'Adour, Pau, France

2 Notre Dame University Louaize, P.O. Box 72, Zouk Mikael, Zouk Mosbeh, Lebanon

3 ESI Group, 3bis rue Saarinen, 94528 Rungis Cedex, France

4 AIRBUS SAS, Allée du Chaffault, Bouguenais, France

5 ESI Chair @ Arts et Métiers Institute of Technology, PIMM Laboratory, 151 Boulevard de l'Hôpital, 75013 Paris, France of appealing properties and low weight, despite their long curing cycle time considered as a disadvantage. The production using conventional processing methods for polymer composite parts usually involve the application of heat to the material by convection or conductive heating, both implying surface heat transfer.

Microwave -MW- technology relies on volumetric heating, which means thermal energy is transferred through electromagnetic fields to materials that can absorb it at specific frequencies. Volumetric heating enables better process temperature control [4] and less overall energy use, which can results in shorter processing cycles [2]. Furthermore, comparable mechanical properties can be shown between parts made with the MW technology and parts made with a traditional curing system (autoclave in the case of $[5,6])$. These virtues of the MW technology attracted industrial production companies as well as researchers in developing the associated heating technology and adopting it for the production of thermoset as well as thermoplastic composite structures.

The main drawback of this technology is that the complex physics involved in the conversion of the electromagnetic energy to thermal energy (heating) is not entirely understood and controlled [3].

The present work aims at describing the interactions of microwaves with a composite laminate composed of a sequence of unidirectional prepreg composite layers (in 
that case carbon fibers impregnated of a polymeric matrix), by simulating the way electromagnetic energy propagates within the material and is converted in thermal energy.

Our previous work [1] addressed the calculation of the propagation of an electromagnetic field in a composite laminate composed of plies whose characteristic in-plane dimension is orders of magnitude higher than the one related to the thickness (typical aspect ratio are of tens of thousands). The present work represents a step forward by numerically coupling the electromagnetic and thermal fields. Therefore, a set up is defined to heat up a laminate plate in a microwave oven and temperature measurements are performed in order to validate experimentally the simulation results.

\section{Materials}

The study is carried out on a composite laminate plate exposed to an electromagnetic field induced in a microwave oven cavity, concretely a Hephaistos 100/100. The dimensions of the cavity is $1050 \times 1470 \times 1800 \mathrm{~mm}$, equipped with 12 magnetrons of $1.2 \mathrm{kw}$ each.

The plate is composed of unidirectional -UD- prepregs involving 64\% (volume fraction) of carbon fibers preimpregnated by a thermoplastic resin. The thickness of one ply is approximately 180 micrometers, and the laminate consists of 25 plies with the following stacking sequence: 11 plies at $0^{\circ}$ and 14 plies at $0^{\circ} / 90^{\circ}$. The stacking was chosen asymmetric to evaluate its impact on the electromagnetic wave penetration.

The whole is surrounded by a thermalimide layer of 60 micrometers, and put into a ceramic mould, coated by

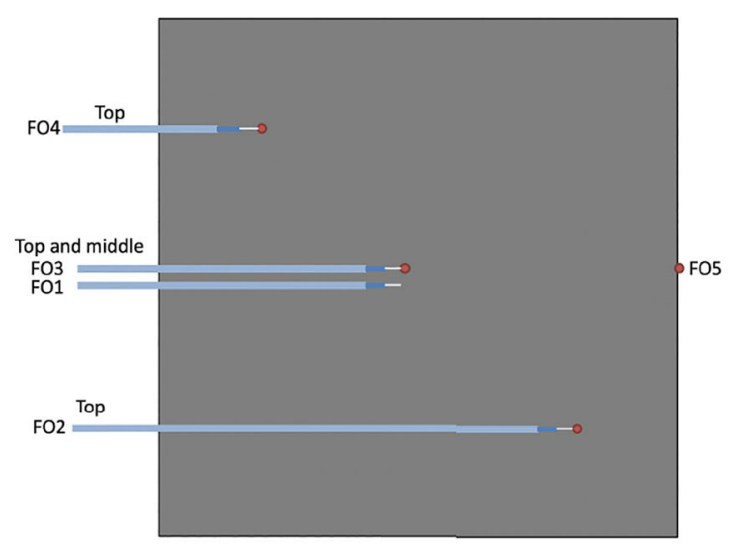

Fig. 1 (Left) Optic fiber sensors inserted in the laminate as well as placed on its top surface during its microwave heating: FO1 is placed inside the laminate, in the interface between the unidirectional plies and the ones with the $0 / 90$ sequencing, FO2, FO3 and FO4 are placed
Table 1 Electromagnetic material properties used in the macro-EMsimulation

\begin{tabular}{llll}
\hline Material & $\epsilon_{r}$ & $\sigma$ & $\mu_{r}$ \\
\hline composite & 20 & 100 & 1.0 \\
mould & 3.54 & 0.28 & 1.0 \\
\hline
\end{tabular}

an enameled ferrite layer (100 micrometers thick). The inplane dimension of the prepreg plate is $300 \times 300 \mathrm{~mm}$ and the dimension of the mould is $600 \times 600 \times 100 \mathrm{~mm}$.

Several optic fibers are positioned in the system as depicted in Fig. 1, to record the temperature evolution inside the laminate plate plate as well as on its top surface during the thermal cycle.

\section{Electromagnetic calculation and heat transfer modeling}

The modeling and simulation consists of three calculations:

1. Macroscopic electromagnetic simulation in the volume of the oven cavity, referred as macro-EM-simulation,

2. Microscopic electromagnetic simulation affecting the composite laminate and its surrounding mould, referred as micro-EM-simulation,

3. Thermal calculation associated with the micro-EMsimulation.

\section{Electromagnetic modeling}

The macro-EM-simulation is first performed by using CEMOne $^{\circledR}$ software by ESI Group. The model related to

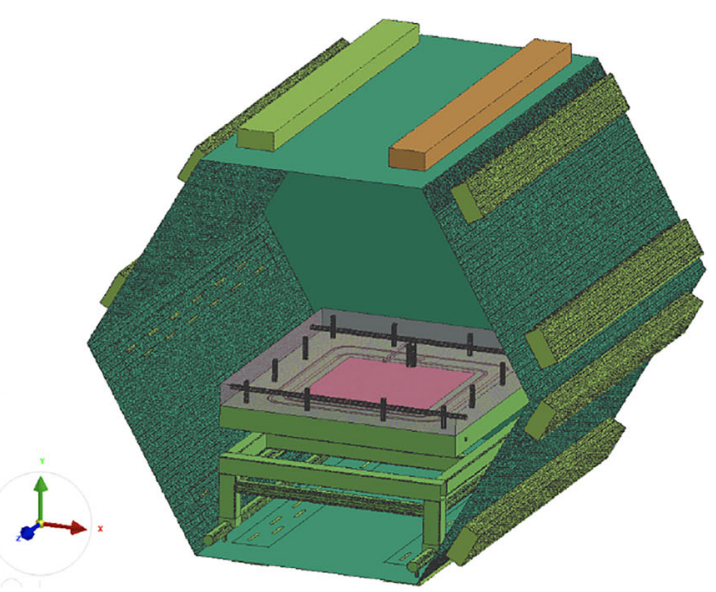

on the laminate top surface, in the interface between the thermalimide and the ferrite layers, and FO5 is placed on a lateral surface of the plate; (Right) Numerical model of the oven $\left(\right.$ CEMOne ${ }^{\circledR}$ software by ESI Group) 


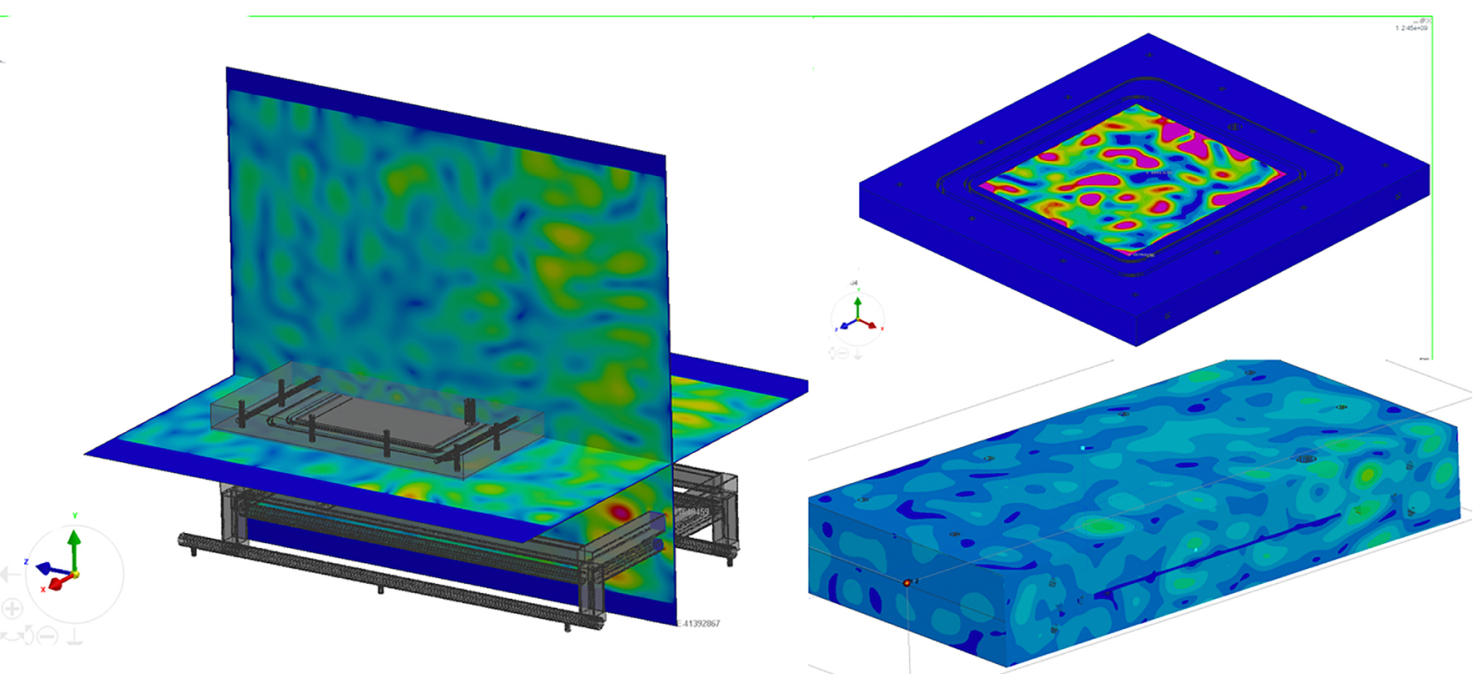

Fig. 2 Macro-EM-simulation: (left) Normalized electric field (V/m) in the whole oven and the volume of interest (surface of the ceramic mould) -bottom right-. The absorbed energy (in w/ $\mathrm{m}^{3}$ ) in the composite laminate (top right -with the upper mould removed for facilitating

the experimental set-up is depicted in Fig. 1(right) where it can be noticed that most of elements are appropriately modelled and included in the numerical model, among them the magnetron waveguides and the table where the mould and part are positioned. However the software resolution is unable to represent the plies involved in the composite laminate, as well as the ferrite layer, ... The characteristic thicknesses are much smaller than the other in-plane characteristic dimensions avoiding the use of an adequate mesh to resolve the rich fields existing at these scales. Thus the numerical model is unable to resolve the ferrite layer and considers a single element along the laminate thickness.

Thus, the volumes occupied by the mould and the composite part are considered as homogenous materials in the macroscopic simulation, with the homogenized material parameters defined in Table 1, that almost correspond to a mixture rule, and whose temperature dependences were ignored because their effects on the EM calculation have an incidence of second order. The macro-EM-simulation is carried out by using a FTDT formulation, by considering

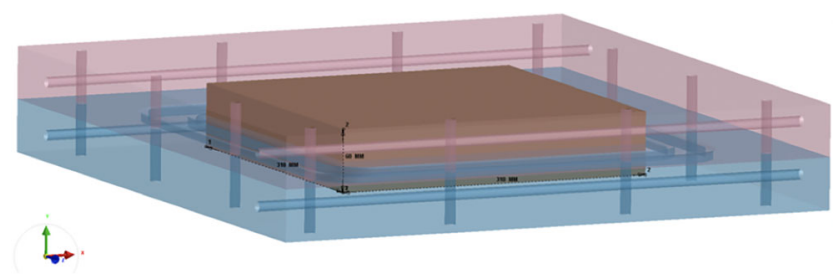

Fig. 3 Volume of interest where the mico-EM-simulation will be performed by considering the electromagnetic field resulting from the macro-EM-simulation on its surface the visualization-) is calculated in the single element disposed along the composite laminate thickness by using the homogenized electromagnetic properties reported in Table 1

more than 34 million of elements with characteristic length of about $1 \mathrm{~mm}$.

The macro-EM-simulation output is the electromagnetic field ampitude everywhere in the oven as depicted in Fig. 2, and more importantly the electromagnetic field amplitude on the surface of the volume of interest depicted in Fig. 3 that will be used in the micro-EM-simulation (that considers a space-frequency formulation [1]) and then in the thermal calculation for evaluating the composite heating. It is important to note that the volume of interest, $\mathcal{V}$, encloses the composite laminate and its surface, $\partial \mathcal{V}$, is comprised within the ceramic mould where the composite laminate is placed. The thickness of $\mathcal{V}$ is $6 \mathrm{~cm}$ whereas the one of the mould enclosing the composite laminate is $10 \mathrm{~cm}$. The composite laminate is centered into $\mathcal{V}$.

As just indicated, the micro-EM-simulation applies in the volume of interest $\mathcal{V}$. The 25 plies laminate previously described is simulated by using the electromagnetic properties reported in Table 2. The composite laminate is surrounded by a ceramic mould coated by a ferrite layer, whose properties are also reported in Table 2.

Table 2 Electromagnetic material properties used in the micro-EMsimulation

\begin{tabular}{llll}
\hline Material & $\epsilon_{r}$ & $\sigma$ & $\mu_{r}$ \\
\hline UD ply - fiber direction & $20+i$ & 1000 & 1.0 \\
UD ply - other plane dir & $20+i$ & 100 & 1.0 \\
UD ply - out of plane dir & $20+i$ & 1 & 1.0 \\
Ferrite layer & $10+0.05 i$ & 50 & $1.2+0.17 i$ \\
Ceramic mould & $5+0.03 i$ & 0.28 & 1.0 \\
\hline
\end{tabular}


Table 3 Homogenized thermal material properties used in the model

\begin{tabular}{llll}
\hline Material & $\rho\left(\mathrm{kg} \mathrm{m}^{-3}\right)$ & $C_{p}\left(\mathrm{~J} \mathrm{~kg}^{-1} \mathrm{~K}^{-1}\right)$ & $K\left(\mathrm{~W} \mathrm{~m}^{-1} \mathrm{~K}^{-1}\right)$ \\
\hline UD ply - fiber direction & 1580 & 1200 & 5.3 \\
UD ply - other plane dir & 1580 & 1200 & 0.62 \\
UD ply - out of plane dir & 1580 & 1200 & 0.62 \\
Ferrite layer & 5000 & 750 & 15 \\
Ceramic mould & 2600 & 1460 & 0.4 \\
\hline
\end{tabular}

To take into account the extremely degenerated domain (characteristic in-plane length to thickness ratio) the inplane-out-of-plane separated representation at the heart of the so-called Proper Generalized Decomposition -PGDis applied as deeply reported in [1]. Thus, the in-plane solutions are achieved by using a mesh consisting of 3960 nodes while 8000 nodes are considered for describing the through-the-thickness solution richness. Such a fine mesh along the thickness direction is compulsory due to the electric field discontinuity at the plies interfaces as well as the boundary layer induced by the attenuation of the electromagnetic wave when penetrating in a conductive material, as it is the case when the electromagnetic wave penetrates the carbon fibers.

The use of a separated representation allows the computation of the fully $3 \mathrm{D}$ solution while solving $2 \mathrm{D}$ and 1D problems with few thousands degrees of freedom each, with a combined equivalent accuracy of an hypothetical 3D calculation involving tens of millions degrees of freedom.

The micro-EM-simulation solution, as described before, uses as boundary conditions the electromagnetic field coming from the macro-EM-simulation solution previously described.

\section{Thermal modeling}

The computed electric and magnetic fields allow the calculation of the induced thermal sources in the domain occupied by the composite material according to

$\mathcal{S}=\frac{1}{2} \Re\left(E \cdot H^{*}\right)$,

acting as source term in the heat equation

$\rho C_{p} \frac{\partial T}{\partial t}-\nabla \cdot(\mathbf{K} \nabla T)=\mathcal{S}$,

where $T$ is the temperature, $\rho$ the density, $C_{p}$ the heat capacity, $\mathbf{K}$ the anisotropic conductivity tensor (refer to Table 3 for the values considered in the numerical applications), $E$ the electric field intensity and $H^{*}$ the magnetic field intensity (the star superscript refers to the complex conjugation) and $\Re$ refers to the complex real part.

In the proposed thermal model the crystallization effect is ignored, as well as its impact on the material thermal properties.
Standard convection boundary conditions are enforced on the mould surfaces $\partial \mathcal{V}$, according to

$-\nabla T \cdot \mathbf{n}=h(\mathbf{x})\left(T-T_{a m b}\right), \quad \mathbf{x} \in \partial \mathcal{V}$,

with $\mathbf{n}$ the unit outwards vector defined on $\partial \mathcal{V}$ and $T_{a m b}$ the ambient temperature (the one of the air occupying the oven). The values of the convection coefficients ( $h$ in Eq. (3)) are given in Table 4.

The numerical solution of the thermal problem is computed by using again the Proper Generalized Decomposition -PGD- method [7] using again the in-plane-out-of-plane separated representation that reads

$T(x, y, z) \approx \sum_{i}^{N} X_{i}(x, y) \cdot Z_{i}(z)$.

This separated representation proved its efficiency for computing thermal and structural problems in such a degenerated geometries [8-10], where it allows the use of a very fine mesh in the thickness direction while ensuring reasonable computing times.

To facilitate the electromagnetic/thermal coupling, the thermal problem is solved using the same meshes than the ones considered for solving the in-plane and throughthe-thickness electromagnetic problems of the micro-EMsimulation.

The four hours process is discretized with a time step of one second and takes few hours calculation by employing a standard laptop.

\section{Results}

The solution of the micro-EM-smulation is shown in Fig. 4 where the electromagnetic field distribution is depicted. The corresponding thermal field is represented in Fig. 5 for two different time instants $t=1000 \mathrm{~s}$ and $t=2500 \mathrm{~s}$. We can notice the hot spots in the middle plane (composite material)

Table 4 Thermal convection coefficients

Convection coefficient with the air $\left(\mathrm{W} / \mathrm{m}^{2} \mathrm{~K}\right)$ 18

Conduction coefficient with the support $\left(\mathrm{W} / \mathrm{m}^{2} \mathrm{~K}\right)$

500 

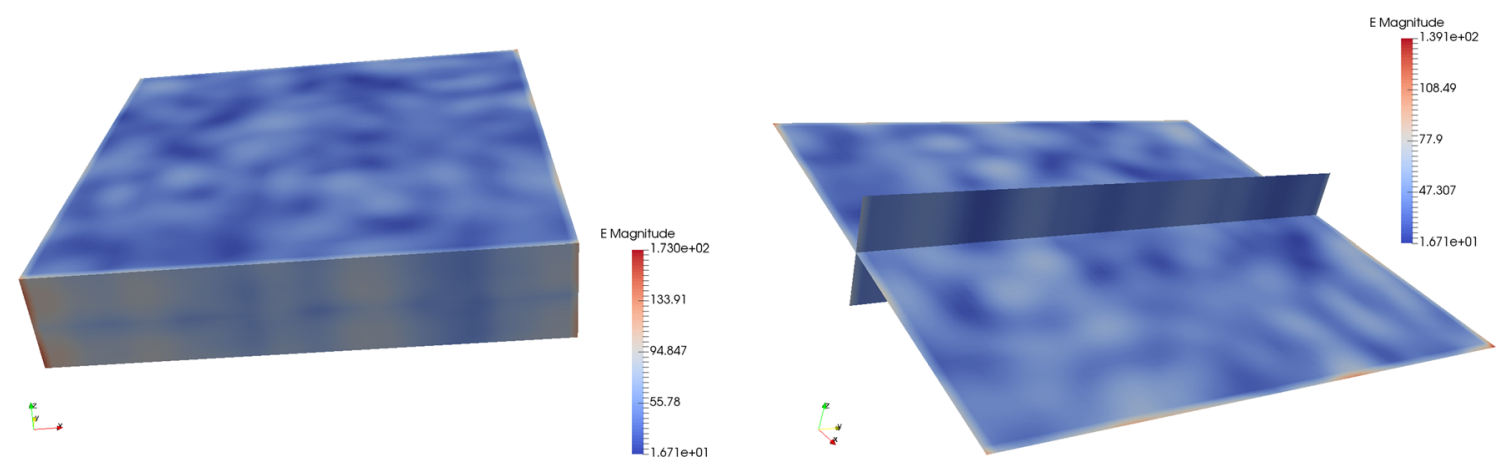

Fig. 4 Snapshot of the micro electromagnetic field in the domain of interest $\mathcal{V}$ (left) and on its middle plane (right)
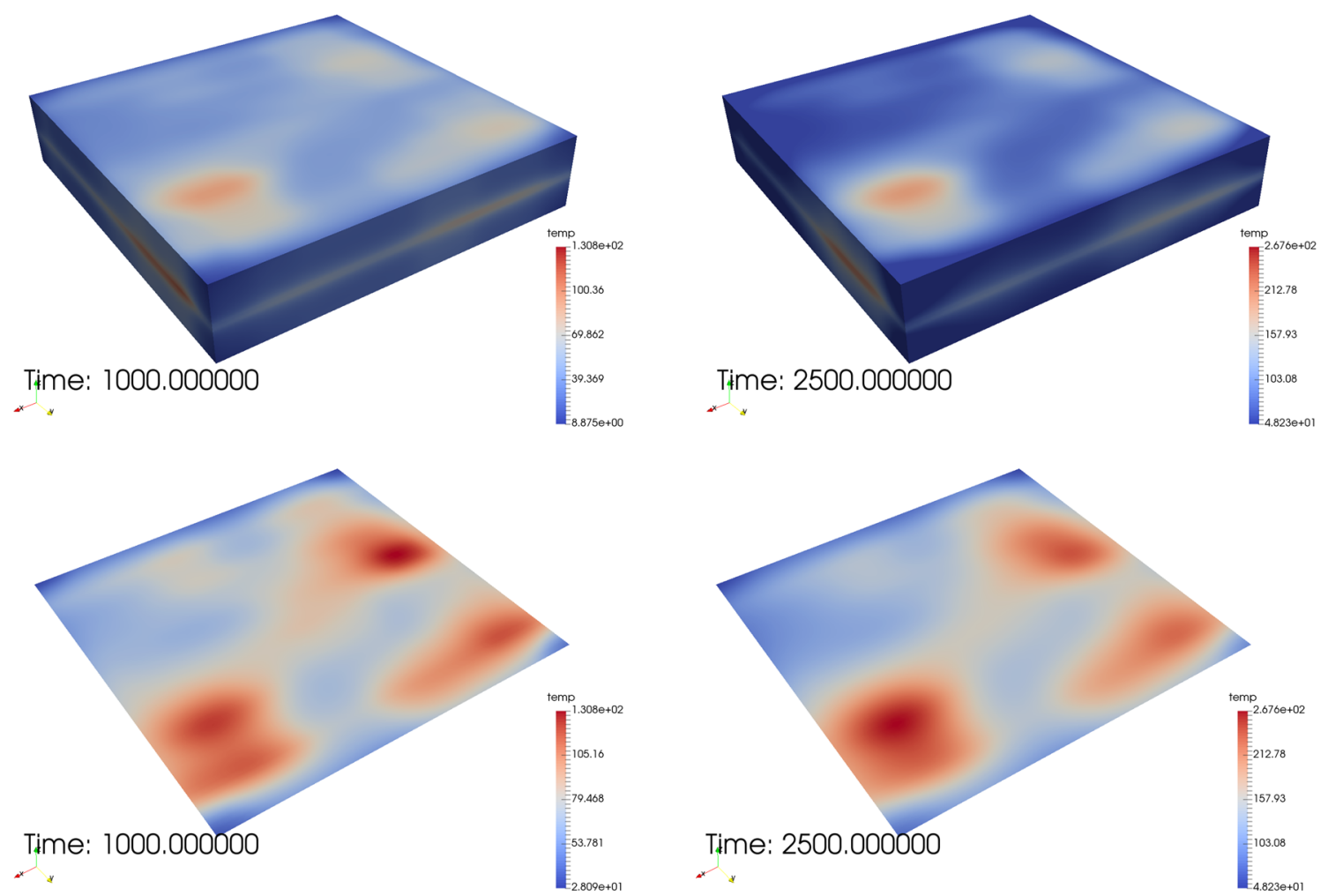

Fig. 5 Snapshots of the temperature field in $\mathcal{V}$ (top) and on the middle plane (bottom) for $t=1000 \mathrm{~s}$ (left) and $t=2500 \mathrm{~s}$ (right)
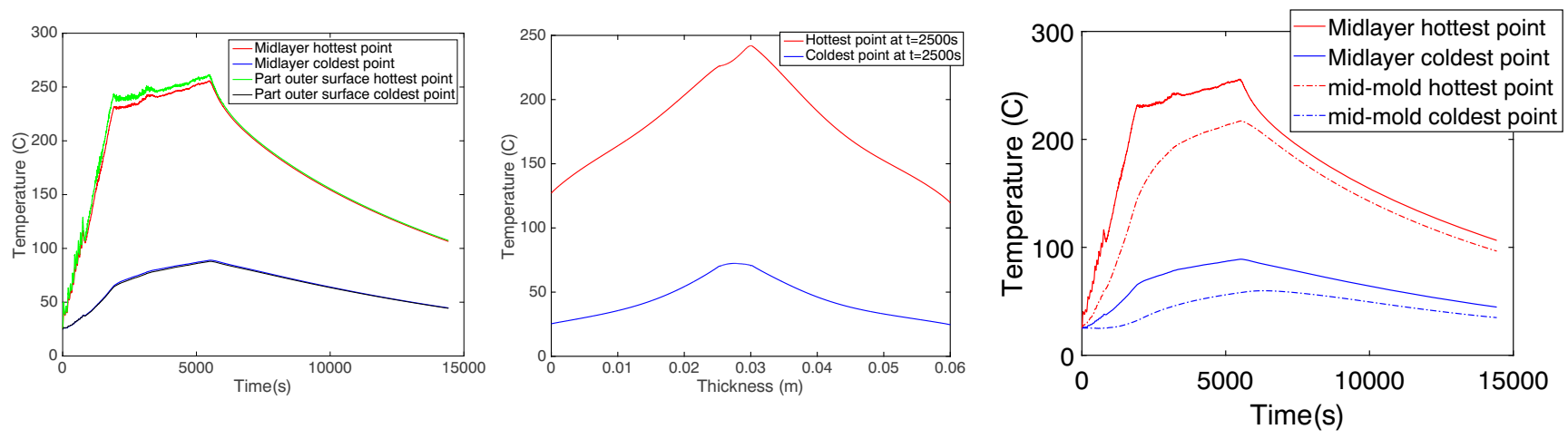

Fig. 6 Minimal and maximal temperature evolution on the top surface and the middle plane of the composite laminate (left), minimal and maximal temperature across the thickness at time $t=2500 \mathrm{~s}$ (middle) and minimal and maximal temperature evolution in the middle plane of the composite and mould (right) 
Fig. 7 Time evolution of the magnetrons "heating" intensity (left) and comparison between the simulated temperature and the experimentally recorded ones (right)
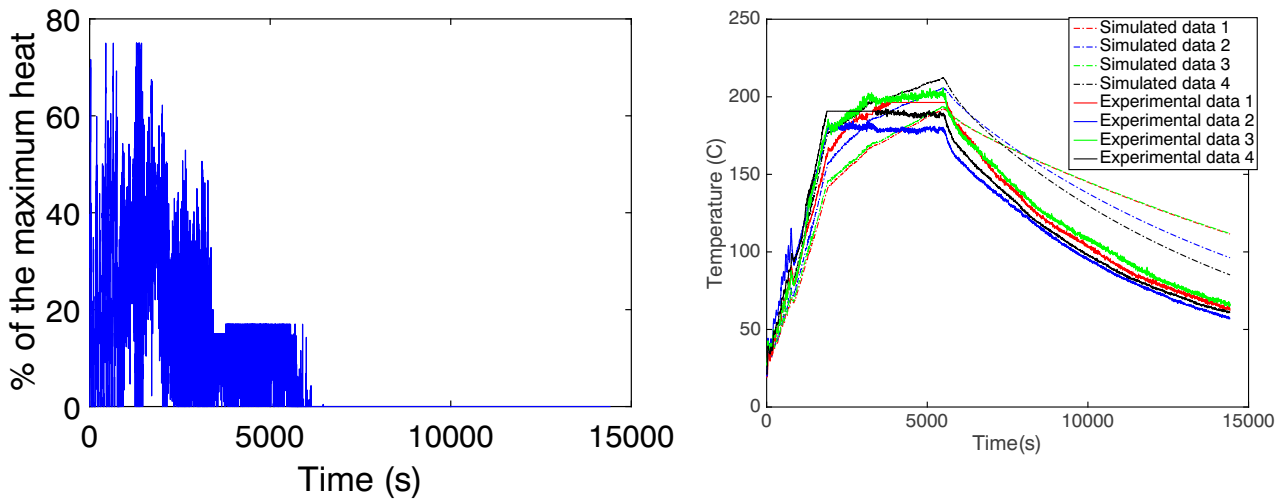

which evolve in time $(t \in[1000,2500] \mathrm{s})$ from $130 \mathrm{C}$ to $267 \mathrm{C}$.

Figure 6 represents the minimal and maximal temperature evolution in different case. The left graph shows the time evolution of the hottest and coldest points in the composite domain (top surface and middle plane). It can be noticed that the temperature distribution is almost the same across the composite laminate thickness. The temperature difference between the hottest and coldest points is extremely high, with more than one hundred degrees difference for the highest temperatures. It seems that the inplane thermal conduction does not suffice for ensuring a temperature homogenization.

\section{Comparison with experiments}

For validating the simulation procedures just described Fig. 7(right) compares the temperature recorded by the different optic fibers and the simulated temperatures for the applied power (left). The agreement seems reasonable, with a quite good representation of the three process stages: the heating, the plateau and the cooling. The accuracy seems reasonable when compared with the very large difference of temperatures between hottest and coldest points just discussed. The noticed deviations could also be due to underestimation of the thermal diffusion as well as to the perturbations induced by the presence of the thermocouples their-self.

A more detailed analysis constitutes a work in progress, that also considers a fully micro-macro electromagnetic coupling to better estimate the induced thermal sources.

\section{Conclusion}

In this work we proposed a simulation tool for coupling the electromagnetic and thermal fields in a composite laminate when subjected to microwave-based processing.

A macroscopic electromagnetic simulation performed by the commercial software CEMOne ${ }^{\circledR}$ (by ESI Group) at the oven level allowed computing the electromagnetic fields on the surface of the domain of interest occupied by the laminated surrounded by the ceramic mould. This electromagnetic field is then used as boundary condition by the so-called micro-EM-simulation that by using the PGD-based in-plane-out-of-plane separated representation calculates with an extremely high resolution all the electromagnetic fields in the domain of interest (mould and laminate). Finally, the electromagnetic induced thermal source is applied as source term in the PGD thermal solver enabling a high-resolution calculation of the temperature field in the composite laminate.

The solution was validated experimentally where a reasonable agreement between predicted and recorded temperatures was noticed.

Acknowledgements This work was partially done in the framework of the Simutool H2020 Project. The authors would like to thank Jasmin Stein from TWI (UK) for the thermal measurements done in the microwave oven, and Remi Chauveau from Loiretech (France) for the tooling and experimental set up.

\section{Compliance with Ethical Standards}

Conflict of interests The authors declare that they have no conflict of interest.

\section{References}

1. Tertrais H, Ibanez R, Barasinski A, Ghnatios $\mathrm{CH}$, Chinesta $\mathrm{F}$ (2019) On the Proper Generalized Decomposition applied to microwave processes involving multilayered components. Math Comput Simul 156:347-363. https://doi.org/10.1016/j.matcom. 2018.09.008

2. Mgbemena C, Li D, Lin M-F, Liddel PD, Katnam KB, Thakur VK, Nezhad HY (2018) Accelerated microwave curing of fibre-reinforced thermoset polymer composites for structural applications: a review of scientific challenges. Compos A: Appl Sci Manuf 115:88-103

3. Zhou J, Li Y, Li N, Liu S, Cheng L, Sui S, Gao J (2018) A multi-pattern compensation method to ensure even temperature in composite materials during microwave curing process. Compos A: Appl Sci Manuf 107:10-20 
4. Mishra RR, Sharma AK (2016) Microwave-material interaction phenomena: Heating mechanisms, challenges and opportunities in material processing. Compos A: Appl Sci Manuf 81:78-97

5. Maenz S, Mühlstädt M, Jandt KD, Bossert J (2015) Mechanical properties of microwave cured glass fibre epoxy composites prepared by resin transfer moulding. J Compos Mater 49(/23):28392847

6. Li N, Li Y, Jelonnek J, Link G, Gao J (2017) A new process control method for microwave curing of carbon fibre reinforced composites in aerospace applications. Compos Part B: Eng 122:61-70

7. Chinesta F, Keunings R, Leygue A (2014) The Proper Generalized Decomposition for advanced numerical simulations. A primer. Springer, Springerbriefs
8. Bognet B, Leygue A, Chinesta F, Poitou A, Bordeu F (2012) Advanced simulation of models defined in plate geometries: 3D solutions with 2D computational complexity. Comput Methods Appl Mech Eng 201:1-12

9. Bognet B, Leygue A, Chinesta F (2014) Separated representations of $3 \mathrm{D}$ elastic solutions in shell geometries. Adv Modell Simul Eng Sci 1:4. http://www.amses-journal.com/content/1/1/4

10. Chinesta F, Leygue A, Bognet B, Ghnatios Ch, Poulhaon F, Bordeu F, Barasinski A, Poitou A, Chatel S, Maison-Le-Poec S (2014) First steps towards an advanced simulation of composites manufacturing by Automated Tape Placement. Int J Mater Form $7(/ 1): 81-92$ 